\title{
The development and use of a research self-efficacy scale to assess the effectiveness of a research training program for academic librarians
}

\author{
Kristine R. Brancolini, Marie R. Kennedy
}

\begin{abstract}
Research self-efficacy - or research confidence - has been shown to be a predictor of research productivity. There is also some evidence that it is a mediating factor between the research training environment and research productivity. To explore the connection between research training and research self-efficacy, the authors developed, validated, and later expanded a scale to measure research self-efficacy among academic librarians. They used an expanded 38item scale to measure the research self-efficacy of participants from a three-year research training workshop for academic librarians, comparing results before and after the workshop. Participants experienced significant increases in research self-efficacy across all 38 questions, within the annual cohorts and across all three years. The question-level results were used to
\end{abstract}

\author{
Authors \\ Kristine R. Brancolini is Dean of the Library at Loyola Marymount University in Los \\ Angeles. She is Co-Director of the Institute for Research Design in Librarianship (IRDL) \\ (irdlonline.org), a U.S. federally-funded program to improve the research skills and productivity \\ of academic librarians. Her current research focuses on assessing the effectiveness of IRDL and \\ identifying research success factors in the development of librarian-researchers. \\ Marie R. Kennedy is a librarian at Loyola Marymount University in Los Angeles, where \\ she coordinates serials and electronic resources. She is the Co-Director of the Institute for \\ Research Design in Librarianship. She writes the Organization Monkey blog (orgmonkey.net) \\ about organization and librarianship. \\ Email: brancoli@1mu.edu
}

Received 22 April 2017

Accepted 14 June 2017 
make changes to the summer workshops in Years 2 and 3, in order to improve the effectiveness of the summer workshop to increase research self-efficacy. This study confirms that a measurement of research self-efficacy can be a useful tool in assessing the effectiveness of research training and improving that training.

\section{Introduction}

The professional role of an academic librarian includes conducting and disseminating the results of research. Academic librarians conduct research for a variety of reasons: to achieve tenure and/or promotion; to engage in evidence-based decision making; to conduct program evaluations and assessments; to advance in the profession; and to demonstrate the value of the library to their users. Researchers have studied the factors that both enable and inhibit research success. In the first article of its kind, Hoffman, Berg, and Koufogiannakis (2014) conducted a comprehensive literature review of empirical studies focused on research success factors, both in librarianship and in other fields. They found that research success requires a number of interrelated conditions. They grouped 16 factors into three categories: "individual attributes, peers and community, and institutional structures and supports" (Hoffman et al., 2014, p. 19), with many factors occurring in more than one category. One of the individual attributes that is a documented predictor of research success is research self-efficacy, conceptualized as "the degree to which an individual believes she or he has the ability to complete various research tasks (e.g., conceptualization, analysis, writing)" (Bieschke, Bishop, \& Garcia 1996, p. 60). The predictive association between research self-efficacy and research productivity has been studied in applied disciplines, such as counseling psychology (Kahn \& Scott, 1997; Phillips \& Russell, 1994) and 
medicine (Bakken, Byars-Winston, \& Wang, 2006). Low research self-efficacy has been associated with research avoidance (Betz, 1986).

In 2010, the authors became interested in the potential for research self-efficacy - or research confidence ${ }^{1}$-- to predict and influence research success among academic librarians. They later realized that it may be an important element in the assessment of research training. The study of self-efficacy requires a domain-specific instrument, a research self-efficacy instrument designed for librarians, but none were found in the literature. In order to measure this success factor among academic librarians, the authors developed an instrument, the Librarian Research Confidence Scale (LRCS-10). The 10-item scale, based on the steps in planning, conducting, and disseminating research, was used in a 2010 online survey of academic librarians (Kennedy \& Brancolini, 2012). This study found that research self-efficacy is a statisticallysignificant predictor of research success among academic librarians. Thinking about the research of Brown, Ryan, Lent, and McPartland (1996) and Hollingsworth and Fassinger (2002), which examined the relationship between research training and research self-efficacy, the authors considered ways to improve the research success of academic librarians by focusing on increasing their research self-efficacy.

In 2013, the authors created a continuing education program for novice librarianresearchers to improve their social science research skills and increase their research productivity. The Institute for Research Design in Librarianship (IRDL) was a year-long program for approximately 20 librarians, funded for three years (2013-2016) by the U.S. federal

\footnotetext{
${ }^{1}$ The authors will use "research self-efficacy" and "research confidence" interchangeably.
} 
agency the Institute of Museum and Library Services (IMLS). ${ }^{2}$ IRDL offered a select group of novice academic and research librarian-researchers, who had enthusiasm for research and a specific research project, a two-part experience: A nine-day summer workshop focused on social science research training through expert instruction, small group activities, and one-on-one consultation with the instructors; followed by a year of advice and moral support with monthly online check-in sessions and communication via social networking tools, including a closed Facebook group, as the participants conduct their research project and prepare the results for dissemination.

During the planning for IRDL, the authors decided to experiment with using self-efficacy to shape the curriculum for, and the assessment of, the summer workshop. However, the confidence scale used in the 2010 survey lacked the granularity necessary to assess the effectiveness of the various components of the workshop. It was first necessary to establish the validity of the instrument, answering the question: Does the scale succeed in measuring the construct of research self-efficacy? The authors conducted Exploratory Factor Analysis (EFA) to establish the validity of the scale. Using the results of the EFA, the authors expanded the scale from 10 items to 38 , elaborating on the steps in the research process. The 38 -item scale, which the authors will call the LRCS-38, has also been validated and since revised; however, the validation of that scale will be addressed in a future article. The same 38 -item scale, the LRCS-

\footnotetext{
${ }^{2}$ More information about IRDL can be found at http://irdlonline.org.
} 
38, was used from 2014 to 2016 in order to ensure consistency across all three cohorts of IRDL Scholars.

The purpose of this article is to describe two related research projects: the first to expand the 10-item Librarian Research Confidence Scale to a more granular, 38-item scale, and the second to use the new instrument as an assessment tool for the IRDL summer research workshop. The first part of the article describes the validation of the LRCS-10, which led to the development of LRCS-38. The authors administered the expanded scale to each participant before and after the workshop. They used these results to assess the effectiveness of the summer research workshop in increasing research self-efficacy and to modify the workshop to boost the participants' research self-efficacy.

The summer workshop incorporates two components of Bandura's model of selfefficacy, mastery experiences and social persuasion $(1993,1997)$, in a research methods learning environment. Both the structure of the workshop and its content are designed to increase research self-efficacy. Increasing research self-efficacy is intended to increase the probability that the IRDL Scholars will complete their research projects and become accomplished, productive librarian-researchers. IRDL offered a unique laboratory for the examination of numerous factors that collectively aim to increase the research productivity of academic librarians and improve the quality of their research.

\section{Literature Review}

Numerous studies have examined the barriers to research success for academic librarians. As practitioner-researchers, librarians experience many of the same difficulties as other 
researchers whose primary responsibilities lie elsewhere, such as social workers, doctors, and clinical psychologists. Some of the obstacles to conducting research are reported as: lack of time to complete a research project; unfamiliarity with the research process; lack of institutional support for research (both emotional and monetary); lack of external research funding; lack of confidence; discouraging jargon; inadequate education in research methods; and lack of motivation (Koufogiannakis \& Crumley, 2006; Miller \& Benefiel, 1998; Powell, Baker, \& Mika, 2002; Wilkinson, 2013). Despite these obstacles, however, many librarians are successfully conducting research and reporting the results of their work. Librarians author the majority of articles in library and information science (LIS) journals (Chang, 2016), including our profession's most highly regarded journals (Galbraith, Smart, Smith, \& Reed, 2014; Luo \& McKinney, 2015). Because of the importance of research success for the professional advancement of academic librarians, librarian-researchers are studying the ways that librarians have overcome the barriers to research, often focusing on institutional support. Other librarianresearchers have taken a more positive approach, identifying a number of factors that lead to the successful completion and dissemination of research: collaboration with one another or other research partners, participating in writing groups, relating their research to practice, and finding a workplace that values and supports research (Fennewald, 2008; Miller \& Benefiel, 1998; Powell et al., 2002; Wilkinson, 2013).

Self-efficacy is a psychological construct developed in the late 1970s and extended over the next two decades by social cognitive theorist Albert Bandura. He believes self-efficacy to be the most powerful influence on initiation and persistence of behavior. Bandura's research found that people tend to avoid tasks they feel exceed their capabilities, while pursuing those they feel 
competent to perform (Bandura, 1994). Perceived self-efficacy - "people's beliefs about their capabilities to produce effects" (Bandura, 1994, p. 71) - has been widely applied to work-related performance and achievement. Research has shown that efficacy beliefs are dynamic; we can change behaviors by changing self-efficacy. For faculty and other professionals who are expected to conduct research as a function of their jobs, research self-efficacy is critical to their success. People with a high degree of research self-efficacy have confidence in their ability to perform successfully the tasks associated with conducting research (Bieschke et al., 1996; Forester, Kahn, \& Hesson-McInnis, 2004).

The relationship between research self-efficacy and research success has been studied in a variety of settings. It has been found to be a predictor of: graduate students' research interest and productivity (Kahn, 2001; Kahn \& Scott, 1997); scholarly productivity among university faculty (Hemmings \& Kay, 2010; Hemmings \& Kay, 2016; Pasupathy \& Siwatu, 2014); and scholarly productivity among professionals, including psychologists (Bieschke, 2006) and physicians (Bakken et al., 2006). These same researchers found that research self-efficacy can be increased through instruction and encouragement. This research on practitioner-researchers is especially relevant to librarians. Members of the practitioner-scientist community similarly struggle with the demands of job performance and conducting research. These findings have broad implications for the education and continuing education of future professionals and working professionals, including academic librarians.

The relationship between research self-efficacy and research training has been studied in the research methods classroom and in related practical courses. Holden, Barker, Meenaghan, and Rosenberg (1999) are the only researchers the authors found who measured research self- 
efficacy in order to assess learning in a research training environment, specifically, a social work graduate program. These researchers developed the Research Self-Efficacy (RSE) scale in order to answer the question: Does social work research education work? (Holden et al., 1999). They set out to measure research self-efficacy to assess the effectiveness of their research education program for social work students. Holden et al. (1999) view research self-efficacy as a subset of social work self-efficacy, just as the authors view research self-efficacy to be a subset of academic librarian self-efficacy. Rather than employ research self-efficacy as a predictor, Holden et al. planned to use it as "an outcome measure for a series of evaluations of social work research education" (Holden et al., 1999, p. 466), which consists of a two-semester research sequence required by the Council on Social Work Education (CSWE). The researchers found statistically significant increases in research self-efficacy over one semester's instruction, both for participants and for each question. Furthermore, in a test to determine if the instruction and research self-efficacy are related, they found a change of approximately one pretest standard deviation, which they deemed to be "educationally meaningful" (Holden et al., 1999, p. 472). Unrau and Beck (2004) also used the RSE instrument to measure changes in research selfefficacy over semester-long courses in social work and speech pathology.

Studying graduate students in counseling psychology, Phillips and Russell (1994) found that research self-efficacy and perceptions of the research training environment each independently contribute to research productivity. However, Brown et al. (1996) thought that the research training environment might be connected to research self-efficacy; an effective research training environment might increase research productivity by increasing research self-efficacy. Brown et al. (1996) reanalyzed a subset of the data (from advanced students only) gathered by 
Phillips and Russell (1994) to test this "mediational hypothesis." The authors confirmed their hypothesis, that research self-efficacy is an "intervening mechanism" between research education and training and research productivity, noting "research self-efficacy beliefs help mediate or explain the relations between research training environments and scholarly productivity" (Brown et al., 1996, p. 543). Hollingsworth and Fassinger (2002) examined the impact of faculty mentors, the research training environment, and research self-efficacy on research productivity among clinical psychology doctoral students. Their results support the findings of Brown et al. (1996); research self-efficacy was a mediator between the research training environment and research productivity. An effective research training environment increases research self-efficacy, which has been found to increase research productivity. However, the authors could find no studies where the measurement of research self-efficacy was used to revise the course or change the learning experience in any way.

Bandura concluded that self-efficacy is not general but specific (2012). In order to measure the complex variable of self-efficacy, researchers must find or develop effective instruments. An individual's sense of efficacy is tied to particular domains of functioning. It varies across activities and circumstances. Instruments are "by necessity tailored to specific domains of functioning and, in many cases, to specific populations" (Maibach \& Murphy, 1995, p. 37). A search of the literature uncovered no research self-efficacy instruments for librarians. In order to measure research self-efficacy among academic librarians, it was necessary to develop a measurement instrument for this population. The authors began with the existing instruments and considered modifying one or more for use with academic librarians. 


\section{Confidence Scale Development and Validation}

There is a variety of instruments for measuring research self-efficacy, most pre-dating Bandura's guidelines (2006), but all include questions on the specific steps in the research process. The authors consulted these articles while developing both versions of the Library Research Confidence Scales, LRCS-10 and LRCS-38. The instruments, and their intended populations, are as follows:

- The Research Self-Efficacy Scale (RSES) (multiple disciplines), developed by Bieschke et al. (1996).

- The Self-Efficacy in Research Measure (SERM) (counseling psychology), developed by Phillips and Russell (1994).

- The Research Self-Efficacy (RSE) scale (social work education), developed by Holden et al. (1999).

- The Clinical Research Appraisal Inventory (CRAI) (academic physicians), developed by Mullikin, Bakken, and Betz (2007).

The first three scales were created to measure research self-efficacy in graduate students, primarily in the social sciences. Bieschke et al. (1996) developed and tested the RSES with doctoral students in the biological sciences, humanities, and physical sciences, in addition to the social sciences. Mullikin et al. (2007) developed the CRAI to assess research self-efficacy within a practitioner-researcher population, academic physicians working in a clinical setting. The scales have been used for a variety of purposes, such as to help students make career decisions (Bieschke et al., 1996) and to assess the effectiveness of research methods courses 
(Holden et al., 1999). These scales have many questions in common, largely constructed around the research process, but each is different based upon the intended population and purpose. None would be appropriate to measure research self-efficacy among academic librarians.

The authors' first Librarian Research Confidence Scale (LRCS) consisted of 10 questions based upon the steps in the research process, with specific emphasis on the types of social science research conducted by librarians (Kennedy \& Brancolini, 2012). It resembles other research self-efficacy scales; however, it is shorter and was considered a preliminary scale. Using a five-point Likert Scale -- 1 = Not at all confident, $2=$ Slightly confident, $3=$ Moderately confident, 4 = Confident, and $5=$ Very confident - - respondents were asked to report on their confidence in their ability to perform the following ten steps in the research process:

1. Turning a topic into a research question.

2. Designing a project to test your question.

3. Performing a literature review.

4. Identifying research partners, if needed.

5. Gathering data.

6. Analyzing data.

7. Reporting results in written format.

8. Reporting results verbally.

9. Determining appropriate format for disseminating results (poster/presentation/article).

10. Identifying appropriate places to disseminate results (publication/conference). 
The authors (2012) included the scale in the 2010 survey to determine the relationship between research confidence and research success among librarians. To measure this possible relationship, the authors asked two related questions on the survey:

- Do you hold a degree in library and information science?

- Have you conducted research since finishing your LIS degree?

By examining the relationships among these variables, the authors found that research self-efficacy may be useful as a predictor for academic librarian research success (Kennedy \& Brancolini, 2012). However, the validity of the scale had yet to be determined.

The authors conducted an Exploratory Factor Analysis (EFA) of the 10-item scale to determine if the questions collectively measured the construct of research self-efficacy. Each question should relate to a subset of questions, clustering into "factors." The statistical analysis revealed that all but two of the questions clustered into a three-factor solution: Planning Phase, Data Phase, and Reporting Phase. The scale items "Performing a literature review” and "Identifying research partners, if needed" did not cluster with the other questions, meaning they did not statistically contribute to the measurement of research self-efficacy, and were removed. The EFA was repeated with the eight-item scale. Cronbach's alpha for the eight-item scale (.898) and the alpha for each factor (Planning $=0.876$, Data $=0.834$, Reporting $=0.860)$ indicate a high level of internal consistency, meaning that all items appear to be measuring the same construct, research self-efficacy. The authors also rewrote the literature review question ("Writing a review of the literature appropriate to your research topic"), based upon the advice of a statistical consultant, to conform more closely with the three factors. The resulting a nine-item scale was used only during the application process for IRDL. Complete results of the EFA were 
reported at the 2014 Library Assessment Conference as part of a report on the first year of IRDL (Brancolini \& Kennedy, 2014).

The authors were interested in using research confidence for two new purposes: development of the curriculum for the IRDL summer research workshop and assessment of its effectiveness. All IRDL applicants completed the revised nine-item scale; those results then contributed to the development of the 2014 summer research workshop curriculum. The workshop seemed to be the perfect environment in which to test the potential causal relationship between research instruction and an increase in research self-efficacy. However, the authors wanted more specificity regarding areas of low and high confidence to guide the further development of IRDL and the assessment of its effectiveness. Elements of the IRDL curriculum could be adjusted to address areas of lower research self-efficacy and areas of higher confidence could be deemphasized. However, the nine-item scale lacked the desired level of specificity. Based upon the results of the EFA, the authors decided to expand the scale within each of the three factors. In 2014, the components of the LRCS-10 were expanded to 38 items in eight categories, which conform to the three-factor solution from the 2010 scale:

\section{Planning Phase}

1.1. Turning a topic into a question that can be tested (3 questions)

1.2. Designing a project to test your question (6 questions)

\subsection{Performing a literature review (5 questions)}

2. Data Phase

2.1. Gathering data (11 questions) 


\subsection{Analyzing data (5 questions)}

3. Reporting Phase

3.1. Reporting results in written format (4 questions)

3.2. Reporting results verbally (2 questions)

3.3. Determining appropriate reporting ( 2 questions)

The expanded survey retained the five-point scale, anchored with $1=$ Not at all confident and $5=$ Very confident. The LRCS-38, the 38-item scale, is reproduced in Appendix 1.

\section{Changes Made to the IRDL Summer Workshop}

To increase participant satisfaction and research self-efficacy, the IRDL team used a variety of feedback methods to make changes to the summer workshop in 2015 and 2016.. These methods included quantitative assessments, such as the results of the LRCS-38 and postworkshop surveys, and qualitative data gathered through evaluative interviews conducted by external reviewers during the workshops. Informal polls taken during the workshops also led to changes. Adjustments to the daily schedule, for example, were made during the workshops based upon participant preferences. Although the workshop curriculum remained largely the same over three years, we implemented several structural changes based on requests from participants. The changes included:

- Assigned readings before the workshop, which led to four textbooks being mailed to IRDL Scholars as soon as the accepted librarians committed to participation. 
- Assigned more homework in the evenings to reduce the amount of time devoted to lecture during the day and to increase the amount of time devoted to hands-on exercises.

- After the first year, increased the time scheduled for writing and consultation with the instructors from one hour per day to two, one hour in the morning right after breakfast and one hour in the afternoon right after lunch.

- After the first year, increased the number of consultants available, adding the external evaluator in Year 2 and the project directors in Year 3.

Over the course of three years, the project directors also adjusted aspects that influenced personal interactions during the workshop (the social persuasion component of Bandura's theory). A library-educator well known for his work related to personal learning networks (PLN) was included in the three grant years to specifically address social persuasion. This instructor was on site for only the first three days of the workshop, to introduce the topic of personal learning networks. He described the purpose of creating a PLN to "build, maintain, and activate connections within an individually orchestrated environment for the purpose of improving learning" (Stephens, 2015).

In Year 1, the instructor provided prompts for the Scholars to write reflective blog posts throughout their workshop experience. The Scholars expressed unease with learning to use blogging software at the same time they were learning about research design. The project directors also considered the amount of time they were asking Scholars to spend reflecting and writing, and in Year 2 arrived at an abbreviated prompt. 
To reduce the stress of learning too many new tools at one time, in Year 2 the instructor shifted to using a communication and discussion format of the Scholars' preference; they selected Reddit and created a private sub-Reddit for the group. The project directors removed the prompt for writing blog posts throughout the workshop and, in its place, gave a single reflective writing assignment about a description of their current PLN and how they expected it to change as their research projects moved forward.

In Year 3, the Scholars were given the opportunity to choose a communication format; this cohort selected Slack as their private chat area. The instructor introduced the video chat program, Collaborate, to the group during his instruction, and met with the group using that software for a chat after he had returned home.

All workshop activities focused on increasing participant research efficacy in an environment conducive to forming a research community. The project team emphasized the comfort and well-being of the participants in addition to providing an effective learning experience. Use of the LRCS-38 provided an opportunity to gather quantitative data regarding research self-efficacy.

\section{Research Questions and Hypotheses}

The authors developed three research questions and hypotheses regarding the relationship between IRDL Scholar research confidence and the summer research workshop, which was held in each of three summers from 2014 to 2016 : 
Q1. Is the IRDL summer workshop effective in increasing the research confidence of the IRDL Scholars?

Null Hypothesis 1: Participating in the workshop will have no impact on the confidence of the IRDL Scholars.

Hypothesis 1: Participating in the workshop will increase the research confidence of all IRDL Scholars.

Q2. Will there be differences in the scores among questions?

Null Hypothesis 2: There will be no increase in the pre- and post-workshop scores on the 38 questions.

Hypothesis 2: There will be an increase in the pre- and post-workshop scores on each of the 38 questions.

Q3. The IRDL team made changes to the summer workshop in 2015 (Year 2) and 2016 (Year 3) based upon multiple program assessments. Did the pre- and post-workshop research confidence of IRDL Scholars increase more in 2015 (Year 2) and 2016 (Year 3), compared to 2014 (Year 1)?

Null Hypothesis 3: There will be no differences between pre- and post-workshop scores, by participant, across the three years (2014 to 2016).

Hypothesis 3: The workshop will increase research confidence between the pre- and post-workshop scores in 2015 and 2016, more so than pre- and post-workshop scores in 2014.

\section{Methods}




\section{Purpose}

The purpose of this study was to measure the effectiveness of the summer research workshop in increasing the research self-efficacy of IRDL Scholars, and to determine if modifications made to the workshop after the first and second years increased the research confidence of the Scholars from 2014 to 2016. Revisions were made to the curriculum and the structure of the summer research workshop following Year 1 of IRDL to increase confidence regarding specific skills and knowledge in Years 2 and 3.

\section{Participants}

The participants were 67 academic and research librarians who were chosen as IRDL Scholars. As the first activity in their yearlong program, they attended the IRDL nine-day summer research workshop: 25 in 2014, 21 in 2015, and 21 in 2016. Participants were competitively selected to attend based upon an application, a research proposal, and a letter of support from their library dean or director. The IRDL Scholars came from 29 states, representing all regions of the United States, from all sizes and types of college and university libraries, and from special research libraries that are not affiliated with academic institutions. Twenty-five percent were male and 75-percent female. Forty-percent were members of ethnic or racial minority groups.

\section{Measures}

To isolate the effects of the summer workshop, the 67 IRDL Scholars completed the LRCS-38 just before the workshop began (Time 1, pre-test) and again at the end of the workshop, following nine days of on-site instruction, mentoring, and networking (Time 2, post- 
test). To ensure that the Scholars felt comfortable stating their true levels of confidence, rather than possibly inflating their levels out of perceived obligation to the IRDL project directors, the researchers requested that the scale be administered via an online survey by a member of the IRDL project assessment team who is a researcher in the university's Office of Institutional Research. Each participant was given a numerical code, which enabled her to match the Time 1 and Time 2 scores. She sent the resulting data to the authors without any personally identifying information.

\section{Results}

Research Question 1/Hypothesis 1

Using SPSS statistical analysis software (Version 22), the authors compared the overall mean scores by participant. Two-tailed paired-samples $t$ tests were performed to measure the differences from Time 1 to Time 2. The descriptive results and $t$-values for the LRCS-38 are presented in Table 1 for the 67 IRDL scholars. At pre-test, the scholars' average level of confidence ranged from an overall low of 45 (of a possible 190) to a high of 132, with a mean of 95. The statistical analysis revealed that Time 2 scores $(M=148.37, S D=17.72)$ by participant were statistically higher than Time 1 scores $(M=95, S D=18.35), t(66)=-20.440, p<.0005$. The null hypothesis is rejected and research hypothesis 1 is confirmed. The confidence scores of the 67 IRDL scholars were statistically higher after the summer research workshop.

\section{Research Question 2/Hypothesis 2}

The authors also performed several statistical tests with regard to the LRCS-38 questions, examining both total scores at Time 1 and Time 2 and individual questions at Time 1 and Time 
2. With regard to individual questions, the average scores are more meaningful than total scores. At Time 1 question averages ranged from a low of 1.24 (of a possible 5) (Pair 29: "Knowing which statistical test(s) to run") to a high of 3.92 (Pair 33: "Knowing how to apply a style guide"). At Time 2, the participants' average level of confidence ranged from an overall low of 114 (of a possible 190) to a high of 184 , with a mean of 148.37 . Their question scores ranged from a low of 2.87 (Pair 29: "Knowing which statistical test(s) to run") to 4.60 (Pair 13: "Using relevant keywords to discover literature about your research topic”).

The analyses revealed that IRDL Scholars scored higher on all 38 items on the confidence scale after the nine-day workshop. Using SPSS, the authors ran paired-samples $t$ tests comparing the question scores for Time 1 and Time 2 . Time 2 scores by question $(M=$ 167.5, $S D=48.61)$ were greater than Time 1 scores $(M=261.60, S D=26.99)$ across the 38 items, $t(37)=-18.529$, two-tailed $p<.0005$. Mean scores at each Time are reported in Table 1. The mean score for each question was greater at Time 2 than at Time 1 . The paired-samples $t$ test for each of the 38 questions was significant (two-tailed) at $p<.0005$. The results of the paired sample $t$ tests are also reported in Table 1. The null hypothesis is rejected and research hypothesis 2 is confirmed. The scores on each question are significantly higher at Time 2 than at Time 1, comparing both overall scores by question and individual scores by question. 


\section{Question}

1. Planning Phase

Q1. 1.1.1. Pair 1

Q2. 1.1.2.

Q3. 1.1.3.

Q4. 1.2.1.

Q5. 1.2.2.

Q6. 1.2.3.

Q7. 1.2.4.

Q8. 1.2.5.

Q9. 1.2.6.

Q10. 1.3.1.

Q11. 1.3.2.

Q12. 1.3.3.

Q13. 1.3.4.

Q14. 1.3.5.

\section{Pair 2}

Pair 3

Pair 4

Pair 5

Pair 6

Pair 7

Pair 8

Pair 9

Pair 10

Pair 11

Pair 12

Pair 13

Pair 14

\section{T1 $M \quad$ T2 $M$ Diff $t$ Values* $^{*}$ (df)}

$3.24 \quad 4.31 \quad 1.07 \quad-10.043(66)$

$\begin{array}{lllll}2.76 & 4.19 & 1.43 & -12.463 & (66)\end{array}$

$\begin{array}{llll}3.10 & 4.27 & 1.17 & -9.174(66\end{array}$

$\begin{array}{lllll}2.51 & 3.94 & 1.43 & -10.897(66)\end{array}$

$\begin{array}{lllll}3.19 & 4.34 & 1.15 & -9.101 & (66)\end{array}$

$\begin{array}{llll}2.25 & 4.16 & 1.91 & -15.702(66)\end{array}$

$\begin{array}{lllll}2.13 & 3.94 & 1.81 & -15.980(66)\end{array}$

$\begin{array}{llll}2.08 & 3.86 & 1.78 & -15.786(65)\end{array}$

$\begin{array}{llll}2.51 & 3.79 & 1.28 & -9.949(66)\end{array}$

$\begin{array}{llll}3.23 & 4.15 & 0.92 & -8.280(66)\end{array}$

$\begin{array}{llll}3.16 & 4.19 & 1.03 & -9.156(66)\end{array}$

$\begin{array}{lllll}3.67 & 4.48 & 0.81 & -6.781 & (66)\end{array}$

$\begin{array}{lllll}3.85 & 4.60 & 0.75 & -7.263(66)\end{array}$

$\begin{array}{lllll}3.64 & 4.58 & 0.94 & -8.864(66)\end{array}$

2. Data Phase

$\begin{array}{llllll}\text { Q15. 2.1.1. } & \text { Pair 15 } & 2.46 & 3.80 & 1.34 & -11.282 \text { (64) }\end{array}$

Q16. 2.1.2. $\quad \begin{array}{llllll} & \text { Pair } 16 & 2.48 & 3.94 & 1.46 & -11.199 \\ \text { (65) }\end{array}$

$\begin{array}{llllll}\text { Q17. 2.1.3. } & \text { Pair } 17 & 1.81 & 3.57 & 1.76 & -12.616(66)\end{array}$

Q18. 2.1.4. $\quad$ Pair $18 \quad 1.94 \quad 4.00 \quad 2.06 \quad-15.532$ (66)

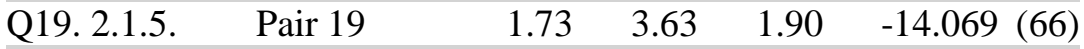

Q20. 2.1.6. $\quad \begin{array}{llllll} & \text { Pair } 20 & 1.99 & 4.03 & 2.04 & -17.149 \\ (66)\end{array}$

$\begin{array}{lllllll}\text { Q21. 2.1.7. } & \text { Pair } 21 & 2.09 & 3.69 & 1.60 & -11.719 & (66)\end{array}$

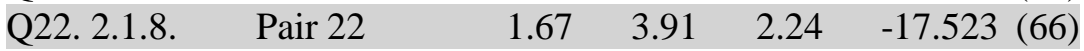

$\begin{array}{llllll}\text { Q23. 2.1.9. } & \text { Pair } 23 & 1.64 & 3.75 & 2.11 & -16.937 \text { (66) }\end{array}$

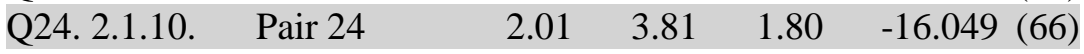

$\begin{array}{llllll}\text { Q25. 2.1.11. } & \text { Pair 25 } & 2.18 & 3.99 & 1.81 & -14.106 \text { (66) }\end{array}$

$\begin{array}{llllll}\text { Q26. 2.2.1. } & \text { Pair } 26 & 1.85 & 3.19 & 1.34 & -9.799 \\ (66)\end{array}$

$\begin{array}{llllll}\text { Q27. 2.2.2. } & \text { Pair } 27 & 1.94 & 3.49 & 1.55 & -10.846 \text { (66) }\end{array}$

Q28. 2.2.3. $\quad$ Pair $28 \quad 1.36 \quad 3.13 \quad 1.77 \quad-11.715$ (66)

$\begin{array}{llllll}\text { Q29. 2.2.4. } & \text { Pair 29 } & 1.24 & 2.87 & 1.63 & -14.005 \text { (66) }\end{array}$

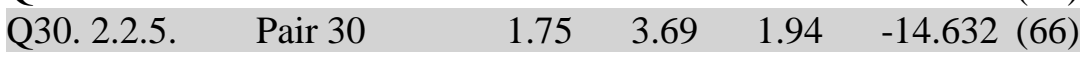

3. Reporting Phase

$\begin{array}{lllllr}\text { Q31. 3.1.1. } & \text { Pair 31 } & 3.06 & 3.81 & 0.75 & -6.478(66) \\ \text { Q32. 3.1.2. } & \text { Pair 32 } & 2.63 & 4.27 & 1.64 & -11.814(66) \\ \text { Q33. 3.1.3. } & \text { Pair 33 } & 3.92 & 4.46 & 0.54 & -4.514(66) \\ \text { Q34. 3.1.4. } & \text { Pair 34 } & 1.70 & 3.04 & 1.34 & -9.571(66) \\ \text { Q35. 3.2.1. } & \text { Pair 35 } & 3.20 & 3.85 & 0.65 & -5.556(65) \\ \text { Q36. 3.2.2. } & \text { Pair 36 } & 3.24 & 3.88 & 0.54 & -5.198(66) \\ \text { Q37. 3.3.1. } & \text { Pair 37 } & 2.97 & 3.97 & 1.00 & -8.585(66) \\ \text { Q38. 3.3.2. } & \text { Pair 38 } & 2.93 & 3.91 & 0.98 & -8.126(66)\end{array}$




\section{Table 1: Paired-Sample Descriptive Statistics and t Values $(N=67)$. *All $t$ values are significant at $p<.0005$}

\section{Research Question 3/Hypothesis 3}

The authors assumed that before the summer workshop the confidence levels of the IRDL Scholars would be statistically equivalent. To test this assumption, the authors analyzed the scores across participants at Time 1 to test the null hypothesis: Before participating in the IRDL summer research workshop, the IRDL Scholars will be equivalent with regard to research confident across all three cohorts, 2014 (Year 1), 2015 (Year 2), and 2016 (Year 3).

The result of single factor analysis of variance (ANOVA) across the three cohorts at Time 1 was $F(2)=1.22, p=.30$, confirming the null hypothesis that the three cohorts are statistically equivalent on the measure of research confidence at Time 1, before the summer research workshop.

The authors analyzed the scores at Time 2 to test the null hypothesis that the three cohorts of IRDL Scholars are equivalent with regard to research confidence after the summer workshop.

The result of single factor ANOVA across the three cohorts at Time 2 was $F(2)=2.93, p$ $=.06$, confirming the null hypothesis and rejecting the hypothesis that there would be differences in research confidence among the cohorts after the summer workshop. Comparing the mean scores for all three cohorts, there is no statistically significant difference; the means are statistically equivalent. However, the authors were specifically interested in comparing means between participants in the first year and second year of IRDL, 2014 and 2015, with the third cohort, which incorporated a number of revisions based upon the Time 2 confidence findings in Years 1 and 2. 
The authors performed two-sample $t$ tests assuming equal variances comparing the Time 2 means for 2014 and 2016 and for 2015 and 2016. The $t$ (44) value comparing the mean confidence scores for 2014 and $2015=-.207$, one-tail $p=.42$, confirming the null hypothesis and rejecting the research hypothesis that research confidence levels will be statistically higher at Time 2 for the 2015 cohort than for 2014 cohort; the pre-workshop scores and the post-workshop scores are statistically equivalent for both cohorts. The $t(44)$ value for 2014 and $2016=-2.38$, one-tail $p=.01$, leading us to reject the null hypothesis, that they are statistically equivalent, and confirming the research hypothesis, that research confidence levels will be statistically higher at Time 2 for participants in the 2016 cohort than for participants in the 2014 cohort. The $t(40)$ value comparing the mean confidence scores for 2015 and $2016=-1.86$, one-tail $p=.035$, also leading us to reject the null hypothesis, that they are statistically equivalent, and confirming the research hypothesis, that research confidence will be higher at Time 2 for participants in the 2016 cohort than for participants in the 2015 cohort.

In summary, the 2016 IRDL Scholars' Time 2 mean scores on the LRCS-38 were statistically higher than the scores for 2014 and 2015; however, there was no statistical difference in the mean Time 2 scores on the LRCS-38 between the 2014 and 2015 IRDL Scholars. See Appendix 2 for the mean scores by question for all three cohorts and for overall changes in average question scores from Time 1 to Time $2(\mathrm{~N}=67)$.

\section{Mapping the LRCS-38 to the IRDL Curriculum}

The statistical analyses of the confidence data do not present the complete picture with regard to the relationship between the IRDL research workshop curriculum and increases in IRDL Scholar research confidence following the workshop. To dig deeper into the data to 
evaluate the appropriateness of the IRDL curriculum and the workshop experience overall, the authors examined specific questions on the LRCS-38 and components of the IRDL curriculum. The authors mapped the LRCS-38 to the IRDL curriculum, to determine areas of low confidence and address them in the curriculum and in the instructional methods employed in the workshop.

The IRDL team focused its attention on the questions that indicated the lowest level of confidence and the highest level of confidence at Time 1, with the goal of increasing the instructional time devoted to areas of low confidence and decreasing the time devoted to areas of high confidence. The five questions with the lowest pre-workshop mean scores were consistent across all three years: Q29, 1.24, "Knowing which statistical test(s) to run”; Q28, 1.36, "Identifying which statistical package may assist you in analyzing your data"; Q23, 1.64, "Knowing how to run a focus group"; Q22, 1.67, "Knowing how to design a focus group"; and Q34, 1.70, "Knowing how to report the results of the statistical test(s) you have run." Identifying these areas of lower confidence enabled the project team to specifically address them in the research workshop. The mean increases for four out of these five questions were among the highest across all three years, with mean increases of more than 1.5 points out of 5: Q29, 1.63; Q28, 1.77; Q23, 2.11; and Q22, 2.24. The increase for Q34 was 1.34. The instructional component of the curriculum on statistical analysis received significant attention in the workshop and was the subject of changes over the three years. The confidence scores were low at Time 1 and continued to be among the lowest at Time 2, but these questions also showed some of the greatest increases in confidence. The analysis of quantitative data would be difficult to address in a nine-day workshop that is devoted to multiple research topics. 
In 2015, the co-directors tried a new approach: assigning more outside reading and inclass activities to reinforce learning. Instead of focusing on exercises using SPSS, the lead instructor assigned tutorials on the use of descriptive and inferential statistics and led the class in an exercise that required them to consider various research scenarios and select appropriate statistical tests. The confidence scores for these questions steadily increased in 2015 and 2016. Planning and conducting focus groups received the same treatment all three years. The summer workshop devoted most of a day to planning and conducting focus groups. Following lecture and discussion, participants were divided into two groups to plan and conduct mock focus groups of their own, with members of the group assigned to critique the process and provide feedback to the group. The two confidence questions about focus groups increased the most of any question, an average of 2.24 points (Design a focus group) and 2.11 points (Conduct a focus group). This effect occurred after Year 1; as a result, the project team decided to increase opportunities for participants to practice specific methods.

The six questions with the highest confidence levels at Time 1 were also consistent across all three years: Q33, 3.92, "Knowing how to apply a style guide"; Q13, 3.85, "Using relevant keywords to discover literature about your research topic"; Q12, 3.67, "Identifying appropriate information sources in which to conduct your literature review"; Q14, 3.64, "Determining if a piece of literature is an appropriate source for your research question"; and Q1 and Q36, both at 3.24, "Turning a topic into a question" and "Knowing how to adapt your written research paper for oral presentation". The mean increases for these six questions were among the lowest across all three years, with mean increases of less than 1 point for five of the questions: Q12, .81; Q13,.75; Q14, .94; Q33, .54; and Q36, .54. The increase for Q1 was 1.07. These questions 
covered topics that received little or no emphasis in the workshop curriculum. The IRDL scholars are confident in their ability to write a literature review; thus, it was not necessary to devote time to this aspect of designing and planning a research study.

\section{Discussion}

The focus of this research self-efficacy study is the assessment of a specific research training program for academic and research librarians working in the United States, the Institute for Research Design in Librarianship (IRDL). The study's primary limitation is that research self-efficacy was used to assess one continuing education program with a relatively small population of 67 librarians. However, this three-year study is an important first step in determining the utility and value of using measures of self-efficacy in the assessment and evaluation of learning. It offers a unique setting for testing research self-efficacy within the context of a research training program, and using the goal of increasing self-efficacy to guide revisions to the training program. The participants have been selected for the program using a standardized application procedure and they have all participated in a structured two-week course with a common goal: Prepare yourself to revise your research proposal and return to your home institution ready to spend the next year conducting the study and preparing the results for dissemination.

The study provided confirmation that each participant in the summer research workshop experienced statistically significant increases in overall and in specific elements of research confidence. Using the results of the LRCS-38 at Time 2, revisions to the summer workshop over three years produced increased confidence from Year 1 to Year 3 and from Year 2 to Year 3. We did not see a significant change in research confidence in Year 2 over Year 1. We made 
changes after Year 1 and Year 2, but we suspect that the cumulative changes had the most impact by Year 3. Although only one of a number of assessments employed during the three-year project, the results of the research confidence survey provided the most specific guidance in revisions to the IRDL summer research workshop.

Individual items of the LRCS-38 discriminated between levels of research confidence before and after the summer research workshop. The IRDL scholars were most confident before the workshop in their ability to conduct a literature review and adapt written results for oral presentation. They were least confident in their ability to plan and conduct focus groups and in planning, conducting, and reporting quantitative analyses. These findings are not surprising, as librarians have had ample opportunity to write literature reviews in graduate school and perhaps in the conduct of previous research. According to Bandura (1997), enactive mastery experiences, in which individuals perform specific behaviors, are most likely to increase selfefficacy. The IRDL workshop provided enactive mastery experiences with regard to planning and conducting focus groups. Conversely, the most common undergraduate majors among academic librarians are history and English (Cross \& Richardson, 1989, p. 30) where they may not have had the opportunity to study and use statistics. Our findings regarding statistics led us to recommend either a statistics course or a review of statistics before arriving at the summer workshop. In a similar research self-efficacy study on social work graduate students, Holden et al. (1999) found similar results with regard to data analysis. The lowest pre-test scores were for the question "Design and implement the best data analysis strategy possible for your study of some aspect of practice," with a mean of 40.7 out of 100 . The post-test score for this same question, after research methods instruction, increased to 65.9, or a difference of 25.2 (Holden et 
al., 1999, p. 470). Our findings confirm the value of using granular measures of research selfconfidence to design and evaluate research instruction.

The LRCS-38 instrument has been a useful assessment tool for IRDL. The authors used it in their 2015 survey of academic librarians (Brancolini \& Kennedy, 2016) and have conducted an exploratory factor analysis (EFA) of the expanded instrument, to be reported in the future. There are some discrepancies between the LRCS-38 and Bandura's guidelines for developing scales to measure self-efficacy. It does not follow three of Bandura's guidelines: the number of points on the response scale, use of a null value at the low end of the scale, and use of the verb 'do' (Bandura, 2006). Bandura believes it is essential that respondents have the opportunity to accurately represent their level of confidence for each question, therefore recommending a 100point scale, specifying that $0=$ Cannot do at all, $50=$ Moderately can do, and $100=$ Highly certain can do. The current study used a five-point Likert scale, $1=$ Not at all confident to $5=$ Very confident, which may have diminished the probability that the scale would discern fine gradations in confidence. Bandura criticized the use of a Likert scale in a recent editorial stating, "Scores that are restricted distort the relation between the variables" (2012, p. 16). However, Likert scales have been widely used in research self-efficacy measurement, and the issue of the 100-point scale versus the five-point scale is unresolved, especially for the purpose of assessing research training. In 2017, the authors revised the LRCS-38 instrument based upon the findings of the EFA and conforming more closely to Bandura's guidelines. It has 33 items and employs a 100-point response scale, includes the null value, and uses 'do' in the response choices. This instrument has been used with the 2017 IRDL cohort, but it must be administered to a larger sample to meet the requirements of EFA. 


\section{Conclusions}

The purpose of this study is to measure the effectiveness of the IRDL summer research workshop in increasing research self-efficacy, and to suggest changes in subsequent years based upon the pre- and post-workshop research self-efficacy results. The authors have established that a research training workshop for novice librarian-researchers can increase research self-efficacy. These findings are likely not specific to IRDL, as researchers in other fields have found similar effects. The nine-day workshop curriculum, taught by experienced social science researchers, explicitly addresses the steps in the research process. Some of the largest gains in research confidence are related to specific workshop content. Other changes in the summer research workshop, such as increasing the number of writing and consultation sessions per day from one to two and the addition of research consultants available to IRDL scholars, may have further contributed to the magnitude of increase in research confidence among the participants from Years 1 and 2 to Year 3.

In 2016, the authors received a second three-year grant from the IMLS (2016-2019) to further refine the IRDL experience to increase the effectiveness of the program. The authors used the 2017 revised version of the LRCS-38 - now the LRCS-33 -- to measure research selfefficacy in the 2017 cohort of IRDL-2. TheIRDL team will continue to refine the use of the LRCS to inform improvements in the summer research workshop and other IRDL-2 activities.

The authors believe that the results of this three-year project have implications for librarians who are planning a research training program and assessing its effectiveness. Although IRDL is a unique program, it shares characteristics of other training programs, including courses and workshops. The LRCS-38 was a useful diagnostic tool for measuring 
confidence in specific steps in the research process before research training occurred, as well as assessing the impact of that training. The process of developing and validating the LRCS has also been a beneficial process, resulting in a scale that might be used reliably by other librarians and library and information science teaching faculty who wish to study the effects of research self-efficacy in other research and practice environments. The LRCS could be modified to include specific components under consideration for a specific training program. The authors found the instrument's granularity especially useful in deciding how to allocate instructional time and emphasis, based upon the low and high areas of confidence. The finding that areas of the lowest confidence respond most favorably to research training is especially encouraging.

\section{References}

Bakken, L. L., Byars-Winston, A., \& Wang, M. (2006). Viewing clinical research career development through the lens of Social Cognitive Career Theory. Advances in Health Sciences Education Theory and Practice, 11(1), 91-110. doi:10.1007/s10459-005-3138-y

Bandura, A. (1993). Perceived self-efficacy in cognitive development and functioning. Educational Psychologist, 28(2), 117-148. doi: 10.1207/s15326985ep2802_3

Bandura, A. (1994). Self-efficacy. In V. S. Ramachandran (Ed.), Encyclopedia of Human Behavior (Vol. 4, pp. 71-81). New York: Academic Press.

Bandura, A. (1997). Self-efficacy: The exercise of control. New York: Freeman.

Bandura, A. (2006). Guide for constructing self-efficacy scales. In F. Pajares \& T. Urdan (Eds.), Self-Efficacy Beliefs in Adolescents (pp. 307-337). Greenwich, CT: Information Age Publications. 
Bandura, A. (2012). On the functional properties of perceived self-efficacy revisited. Journal of Management, 38(1), 9-44. doi: 10.1177/0149206311410606

Betz, N. E. (1986). Research training in counseling psychology: Have we addressed the real issues? The Counseling Psychologist, 14(1), 107-113.

Bieschke, K. J. (2006). Research self-efficacy beliefs and research outcome expectations: Implications for developing scientifically minded psychologists. Journal of Career Assessment, 14(1), 77-91. doi: 10.1177/1069072705281366

Bieschke, K. J., Bishop, R. M., \& Garcia, V. L. (1996). The utility of the research self-efficacy scale. Journal of Career Assessment, 4(1), 59-75.

Brancolini, K. R., \& Kennedy, M. R. (2014, 4-6 August). Measuring the research readiness of academic and research librarians: A project report of the Institute for Research Design in Librarianship (IRDL). Building Effective, Sustainable, Practical Assessment:

Proceedings of the 2014 Library Assessment Conference. Washington, D.C.: Association of Research Libraries (pp. 188-193). Retrieved from:

\section{http://libraryassessment.org/bm doc/proceedings-lac-2014.pdf}

Brancolini, K. R., \& Kennedy, M. R. (2016, May). Academic librarian research: An update to a survey of attitudes, involvement, and perceived capabilities. Presentation at Qualitative and Quantitative Methods in Libraries (QQML), London, England. Retrieved from: https://works.bepress.com/kristine_brancolini/18/ 
Brown, S. D., Lent, R.W., Ryan, N. E., \& McPartland, E. B. (1996). Self-efficacy as in intervening mechanism between research training environments and productivity: A theoretical and methodological extension. The Counseling Psychologist, 24(3), 535-544.

Chang, Y. W. (2016). Characteristics of articles co-authored by researchers and practitioners in library and information science journals. The Journal of Academic Librarianship, 42(5), 535-541. doi: 10.1016/j.acalib.2016.06.021

Cross, B. M., \& Richardson, J. (1989). The educational preparation of government information specialists. Journal of Education for Library and Information Science, 30(1), 28-38.

Fennewald, J. (2008). Research productivity among librarians: Factors leading to publication at Penn State. College \& Research Libraries, 69(2), 104-116.

Forester, M., Kahn, J. H., \& Hesson-McInnis, M. S. (2004). Factor structures of three measures of research self-efficacy. Journal of Career Assessment, 12(1), 3-16. doi: $10.1177 / 1069072703257719$

Galbraith, Q., Smart, E., Smith, S.D., \& Reed, M. (2014). Who publishes in top-tier library science journals? An analysis by faculty status and tenure. College \& Research Libraries, 75 (5), 724-735. doi: 10.5860/crl.75.5.724

Hemmings, B., \& Kay, R. (2010). Research self-efficacy, publication output, and early career development. International Journal of Educational Management, 24(7), 562-574. doi: $10.1108 / 09513541011079978$

Hemmings, B., \& Kay, R. (2016). The relationship between research self-efficacy, research disposition and publication output. Educational Psychology: An International Journal of 
Experimental Educational Psychology, 36(2), 347-361. doi:

$10.1080 / 01443410.2015 .1025704$

Hoffman, K., Berg, S., \& Koufogiannakis, D. (2014). Examining success: Identifying factors that contribute to research productivity across librarianship and other disciplines. Library and Information Research, 38(119), 13-28. Retrieved from:

\section{http://www.lirgjournal.org.uk/lir/ojs/index.php/lir/article/view/639}

Holden, G., Barker, K., Meenaghan, T., \& Rosenberg, G. (1999). Research self-efficacy: A new possibility for educational outcomes assessment. Journal of Social Work Education, 35(3), 463-476. doi: 10.1080/10437797.1999.10778982

Hollingsworth, M. A., \& Fassinger, R. E. (2002). The role of faculty mentors in the research training of counseling psychology doctoral students. Journal of Counseling Psychology, 49(4), 324-330.

Kahn, J. H. (2001). Predicting the scholarly activity of counseling psychology students: A refinement and extension. Journal of Counseling Psychology, 48(3), 344-354. doi: 10.1037/0022-0167.48.3.344

Kahn, J. H., \& Scott, N. A. (1997). Predictors of research productivity and science-related career goals among counseling psychology doctoral students. The Counseling Psychologist 25(1), 38-67.

Kennedy, M. R., \& Brancolini, K. R. (2012). Academic librarian research: A survey of attitudes, involvement, and perceived capabilities. College \& Research Libraries, 73(5), 431-448.

Koufogiannakis, D., \& Crumley, E. (2006). Research in librarianship: Issues to consider. Library Hi Tech, 24(3), 324-340. 
Luo, L., \& McKinney, M. (2015). JAL in the past decade: A comprehensive analysis of academic library research. The Journal of Academic Librarianship, 41(2), 123-129. doi: 10.1016/j.acalib/2015.01/003

Maibach, E., \& Murphy, D. A. (1995). Self-efficacy in health promotion research and practice: Conceptualization and Measurement. Health Education Research: Theory \& Practice, $10(1), 37-50$.

Miller, J. P., \& Benefiel, C. R. (1998). Academic librarians and the pursuit of tenure: The support group as a strategy for success. College \& Research Libraries, 59(3), 260-265.

Mullikin, E. A., Bakken, L. L., \& Betz, N. E. (2007). Assessing research self-efficacy in physician-scientists: The Clinical Research Appraisal Inventory. Journal of Career Assessment, 15(3), 367-387. doi: 10.1177/1069072707301232

Pasupathy, R., \& Siwatu, K. O. (2014). An investigation of research self-efficacy beliefs and research productivity among faculty members at an emerging research university in the USA. Higher Education Research \& Development, 33(4), 728-741. doi: $10.1080 / 07294360.2013 .863843$

Phillips, J. C., \& Russell, R. K. (1994). Research self-efficacy, the research training environment, and research productivity among graduate students in counseling psychology. The Counseling Psychologist, 22(4), 628-641.

Powell, R. R., Baker, L. M., \& Mika, J. J. (2002). Library and information science practitioners and research. Library and Information Science Research, 24(1), 49-72.

Stephens, M. (2015). Personal learning networks and reflective practice. Unpublished IRDL teaching notes. 
Unrau, Y. A., \& Beck, A. R. (2004). Increasing research self-efficacy among student in professional academic programs. Innovative Higher Education, 28(3), 187-204.

Wilkinson, Z. (2013). Rock around the tenure clock: Research strategies for new academic librarians. New Library World, 114(1/2), 54-66.

\section{Appendix 1: Librarian Research Confidence Scale (LRCS-38)}

On a scale of 1 to 5, with 1 being "Not at all confident" and 5 being "Very confident," how would you rate your confidence in performing the following steps in a research project?

Scale: 1 = Not at all confident; 2 = Slightly confident; 3 = Moderately confident; $4=$ Confident; 5 = Very confident

\section{Planning Phase}

\subsection{Turning a topic into a question that can be tested}

1.0.1. Turning your topic into a question. (Pair 1)

1.0.2. Constructing a question that is reasonable in scope. (Pair 2)

1.0.3. Determining if your research topic makes a contribution to the field. (Pair 3)

\subsection{Designing a project to test your question}

1.0.4. Designing a project to answer your question. (Pair 4)

1.0.5. Identifying other research studies similar to yours in order to examine the methods used. (Pair 5)

1.0.6. Exploring research designs that are appropriate for your question. (Pair 6) 1.0.7. Choosing a research design that is appropriate for your question. (Pair 7) 
1.0.8. Selecting the methods and procedures for your question. (Pair 8)

1.0.9. Developing a timeline for the study. (Pair 9)

\subsection{Performing a literature review}

1.0.10. Writing a review of the literature appropriate for your research topic. (Pair 10)

1.0.11. Determining how your study can contribute to the existing literature. (Pair 11)

1.0.12. Identifying appropriate information sources in which to conduct your literature search. (Pair 12)

1.0.13. Using relevant keywords to discover literature about your research topic. (Pair 13)

1.0.14. Determining if a piece of literature is an appropriate source for your research question. (Pair 14)

\section{Data Phase}

\subsection{Gathering data}

2.1.1. Gathering data. (Pair 15)

2.1.2. Determining which members of a population to include in your study. (Pair 16)

2.1.3. Determining how many members of a population to include in your study. (Pair

17)

2.1.4. Choosing appropriate qualitative data collection techniques. (Pair 18)

2.1.5. Choosing appropriate quantitative data collection techniques. (Pair 19)

2.1.6. Choosing an appropriate data gathering procedure. (Pair 20)

2.1.7. Identifying appropriate sources of existing data. (Pair 21)

2.1.8. Knowing how to design a focus group. (Pair 22) 
2.1.9. Knowing how to run a focus group. (Pair 23)

2.1.10. Knowing how to design a survey. (Pair 24)

2.1.11. Knowing how to administer a survey. (Pair 25)

\subsection{Analyzing data}

2.2.1. Analyzing data. (Pair 26)

2.2.2. Knowing how to organize the data you have gathered. (Pair 27)

2.2.3. Identifying which statistical package may assist you in analyzing your data. (Pair

28)

2.2.4. Knowing which statistical test(s) to run. (Pair 29)

2.2.5. Knowing how to code qualitative data to identify themes and sub-themes. (Pair

30)

\section{Reporting Phase}

\subsection{Reporting results in written format.}

3.1.1. Reporting results in written format. (Pair 31)

3.1.2. Knowing the components to construct a traditional social sciences journal article. (Pair 32)

3.1.3. Knowing how to apply a style guide. (Pair 33)

3.1.4. Knowing how to report the results of the statistical test(s) you may have run. (Pair 34)

\subsection{Reporting results verbally.}

3.2.1. Reporting results verbally. (Pair 35) 
3.2.2. Knowing how to adapt your written research paper for oral presentation. (Pair 36)

3.3. Determining appropriate reporting.

3.3.1. Determining an appropriate format for disseminating results. (Pair 37)

3.3.2. Identifying appropriate places to disseminate results. (Pair 38)

Appendix 2: Changes in Mean Scores on LRCS-38 Time 1 (T1) to Time 2 (T2) by Year 


\begin{tabular}{|c|c|c|c|c|}
\hline $\begin{array}{l}\text { Question on Librarian Research } \\
\text { Confidence Scale (LRCS-38) }\end{array}$ & $\begin{array}{l}2014 \\
\text { T1 to T2 } \\
(\mathbf{N}=25)\end{array}$ & $\begin{array}{l}2015 \\
\text { T1 to T2 } \\
(\mathbf{N}=21)\end{array}$ & $\begin{array}{l}2016 \\
\text { T1 to T2 } \\
(\mathbf{N}=21)\end{array}$ & $\begin{array}{l}\text { T1 to T2 } \\
\text { Mean } \\
\text { Differences on } \\
\text { Confidence } \\
\text { Scale }(N=67) \\
\end{array}$ \\
\hline $\begin{array}{l}\text { 1.1.1. Turning your topic into a } \\
\text { question (Pair 1) }\end{array}$ & 1.12 & 0.90 & 1.19 & 1.07 \\
\hline $\begin{array}{l}\text { 1.1.2. Constructing a question } \\
\text { that is reasonable in scope. (Pair 2) }\end{array}$ & 1.52 & 1.19 & 1.57 & 1.43 \\
\hline $\begin{array}{l}\text { 1.1.3. Determining if your } \\
\text { research topic makes a contribution } \\
\text { to the field. (Pair 3) }\end{array}$ & 1.36 & 0.76 & 1.34 & 1.17 \\
\hline $\begin{array}{l}\text { 1.2.1. Designing a project to } \\
\text { answer your question. (Pair 4) }\end{array}$ & 1.48 & 1.62 & 1.19 & 1.43 \\
\hline $\begin{array}{l}\text { 1.2.2. Identifying other research } \\
\text { studies similar to yours in order to } \\
\text { examine the methods used. (Pair 5) }\end{array}$ & 1.40 & 1.05 & 0.95 & 1.15 \\
\hline $\begin{array}{l}\text { 1.2.3. Exploring research designs } \\
\text { that are appropriate for your } \\
\text { question. (Pair 6) }\end{array}$ & 1.96 & 1.71 & 2.05 & 1.91 \\
\hline $\begin{array}{l}\text { 1.2.4. Choosing a research } \\
\text { design that is appropriate for your } \\
\text { question. (Pair 7) }\end{array}$ & 1.60 & 2.00 & 1.86 & 1.81 \\
\hline $\begin{array}{l}\text { 1.2.5. Selecting the methods and } \\
\text { procedures for your question. (Pair } \\
\text { 8) }\end{array}$ & 1.60 & 1.90 & 1.90 & 1.78 \\
\hline $\begin{array}{l}\text { 1.2.6. Developing a timeline for } \\
\text { the study. (Pair 9) }\end{array}$ & 1.20 & 1.24 & 1.42 & 1.28 \\
\hline $\begin{array}{l}\text { 1.3.1. Writing a review of the } \\
\text { literature appropriate for your } \\
\text { research topic. (Pair 10) }\end{array}$ & 1.00 & 0.81 & 0.91 & 0.92 \\
\hline $\begin{array}{l}\text { 1.3.2. Determining how your } \\
\text { study can contribute to the existing } \\
\text { literature. (Pair 11) }\end{array}$ & 1.12 & 0.76 & 1.19 & 1.03 \\
\hline $\begin{array}{l}\text { 1.3.3. Identifying appropriate } \\
\text { information sources in which to } \\
\text { conduct your literature search. (Pair } \\
\text { 12) }\end{array}$ & 0.76 & 0.81 & 0.86 & 0.81 \\
\hline $\begin{array}{l}\text { 1.3.4. Using relevant keywords } \\
\text { to discover literature about your } \\
\text { research topic. (Pair 13) }\end{array}$ & 0.68 & 0.76 & 0.80 & 0.75 \\
\hline $\begin{array}{l}\text { 1.3.5. Determining if a piece of } \\
\text { literature is an appropriate source } \\
\text { for your research question. (Pair } \\
\text { 14) }\end{array}$ & 0.96 & 0.76 & 1.10 & 0.94 \\
\hline 2.1.1. Gathering data. (Pair 15) & 1.38 & 1.14 & 1.52 & 1.34 \\
\hline $\begin{array}{l}2.1 .2 \text {. Determining which members } \\
\text { of a population to include in your } \\
\text { study. (Pair 16) }\end{array}$ & 1.50 & 1.19 & 1.67 & 1.46 \\
\hline
\end{tabular}




\begin{tabular}{|c|c|c|c|c|}
\hline $\begin{array}{l}\text { 2.1.3. Determining how many } \\
\text { members of a population to include } \\
\text { in your study. (Pair 17) }\end{array}$ & 1.84 & 1.38 & 2.05 & 1.76 \\
\hline $\begin{array}{l}\text { 2.1.4. Choosing appropriate } \\
\text { qualitative data collection } \\
\text { techniques. (Pair 18) }\end{array}$ & 1.84 & 1.90 & 2.47 & 2.06 \\
\hline $\begin{array}{l}\text { 2.1.5. Choosing appropriate } \\
\text { quantitative data collection } \\
\text { techniques. (Pair 19) }\end{array}$ & 1.68 & 1.81 & 2.23 & 1.90 \\
\hline $\begin{array}{l}\text { 2.1.6. Choosing an appropriate data } \\
\text { gathering procedure. (Pair 20) }\end{array}$ & 1.80 & 1.81 & 2.58 & 2.04 \\
\hline $\begin{array}{l}\text { 2.1.7. Identifying appropriate } \\
\text { sources of existing data. (Pair 21) }\end{array}$ & 1.40 & 1.29 & 2.14 & 1.60 \\
\hline $\begin{array}{l}\text { 2.1.8. Knowing how to design a } \\
\text { focus group. (Pair 22) }\end{array}$ & 2.20 & 1.81 & 2.71 & 2.24 \\
\hline $\begin{array}{l}\text { 2.1.9. Knowing how to run a focus } \\
\text { group. (Pair 23) }\end{array}$ & 2.24 & 1.62 & 2.43 & 2.11 \\
\hline $\begin{array}{l}\text { 2.1.10. Knowing how to design a } \\
\text { survey. (Pair 24) }\end{array}$ & 1.64 & 1.81 & 1.95 & 1.80 \\
\hline $\begin{array}{l}\text { 2.1.11. Knowing how to administer } \\
\text { a survey. (Pair 25) }\end{array}$ & 1.72 & 1.52 & 2.19 & 1.81 \\
\hline 2.2.1. Analyzing data.(Pair 26) & 1.36 & 0.95 & 1.72 & 1.34 \\
\hline $\begin{array}{l}\text { 2.2.2. Knowing how to organize the } \\
\text { data you have gathered. (Pair } 27 \text { ) }\end{array}$ & 1.60 & 1.05 & 2.00 & 1.55 \\
\hline $\begin{array}{l}\text { 2.2.3. Identifying which statistical } \\
\text { package may assist you in } \\
\text { analyzing your data. (Pair 28) }\end{array}$ & 1.96 & 1.24 & 2.10 & 1.77 \\
\hline $\begin{array}{l}\text { 2.2.4. Knowing which statistical } \\
\text { test(s) to run. (Pair 29) }\end{array}$ & 1.44 & 1.67 & 1.81 & 1.63 \\
\hline $\begin{array}{l}\text { 2.2.5. Knowing how to code } \\
\text { qualitative data to identify themes } \\
\text { and sub-themes. (Pair 30) }\end{array}$ & 1.88 & 1.76 & 2.19 & 1.94 \\
\hline $\begin{array}{l}\text { 3.1.1. Reporting results in written } \\
\text { format. (Pair } 31 \text { ) }\end{array}$ & 0.84 & 0.57 & 0.80 & 0.75 \\
\hline $\begin{array}{l}\text { 3.1.2. Knowing the components to } \\
\text { construct a traditional social } \\
\text { sciences journal article. (Pair 32) }\end{array}$ & 1.84 & 1.43 & 1.62 & 1.64 \\
\hline $\begin{array}{l}\text { 3.1.3. Knowing how to apply a } \\
\text { style guide. (Pair 33) }\end{array}$ & 0.52 & 0.57 & 0.52 & 0.54 \\
\hline $\begin{array}{l}\text { 3.1.4. Knowing how to report the } \\
\text { results of the statistical test(s) you } \\
\text { may have run. (Pair } 34 \text { ) }\end{array}$ & 1.16 & 1.24 & 1.67 & 1.34 \\
\hline $\begin{array}{l}\text { 3.2.1. Reporting results verbally. } \\
\text { (Pair 35) }\end{array}$ & 0.76 & 0.38 & 0.80 & 0.65 \\
\hline $\begin{array}{l}\text { 3.2.2. Knowing how to adapt your } \\
\text { written research paper for oral } \\
\text { presentation. (Pair 36) }\end{array}$ & 0.56 & 0.29 & 1.09 & 0.64 \\
\hline $\begin{array}{l}\text { 3.1.1. Determining an appropriate } \\
\text { format for disseminating results. } \\
\text { (Pair 37) }\end{array}$ & 1.16 & 0.52 & 1.28 & 1.00 \\
\hline
\end{tabular}


3.1.2. Identifying appropriate places to disseminate results. (Pair 38)

\begin{tabular}{|l|l|l|l|}
\hline 1.24 & 0.71 & 0.95 & 0.98 \\
\hline
\end{tabular}

